\title{
EFEITO DO SISTEMA IMUNOLÓGICO FRENTE AO EXERCICIO FISICO
}

DOI: $10.48140 /$ digitaleditora.2020.002.17

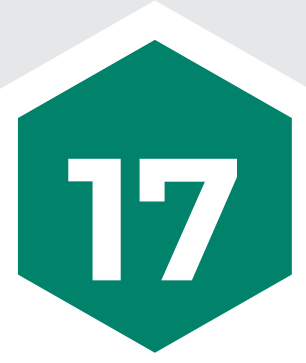

RESUMO

Objetivos: Desta maneira o presente estudo tem como objetivo analisar a resposta do sistema imunológico frente o exercício físico em diferentes intensidades.

Métodos: Trata-se de um estudo de pesquisa bibliográfica com base em revistas e artigos científicos para avaliar o efeito do sistema imunológico frente ao exercício físico em suas diferentes intensidades, para organização desse objeto de estudo foram lidas e interpretadas revistas e assuntos de artigos com intuito de gerar um esclarecimento do caso em estudo, tais como PubMed, Scielo. O estudo foi realizado considerando uma busca pra apresentar a importância sobre o assunto através de alguns estudos de 5 anos pra cá.

Resultados: Foram analisados artigos de revistas com efeito do exercício físico no sistema imunológico, onde foi possível analisar e observar que o sistema imune pode ter um benéfico de acordo com a intensidade aplicada

Conclusão: Vale considerar na prescrição do treinamento calcular e periodizar a atividade prescrita para assim podermos ter um controle da intensidade do exercício físico em relação ao sistema imune.

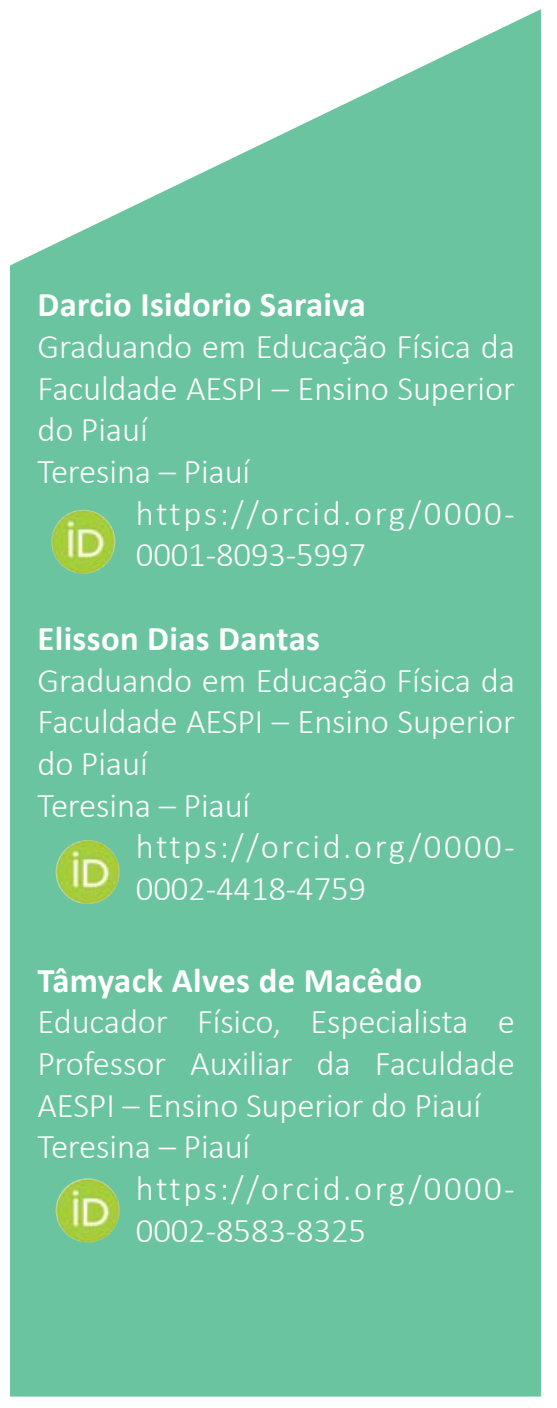

PALAVRAS-CHAVES: Exercício físico. Sistema imune. Linfócitos. Neutrófilos. Macrófagos. Células Natural Killer. 


\section{EFFECT OF THE IMMUNOLOGICAL SYSTEM FRONT OF PHYSICAL EXERCISE}

DOI: $10.48140 /$ digitaleditora.2020.002.17

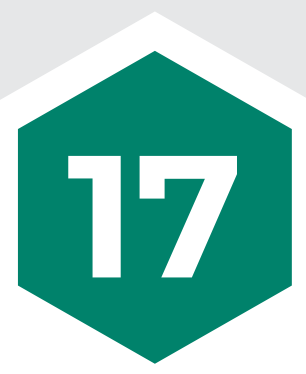

ABSTRACT

Recebido em: 10/12/2020

Aprovado em: 28/12/2020

Conflito de Interesse: não

Suporte Financeiro: não houve

Objectives: Thus, the present study aims to analyze the response of the immune system to physical exercise at different intensities.

Methods: This is a bibliographic research study based on journals and scientific articles to evaluate the effect of the immune system on physical exercise in its different intensities, for the organization of this object of study, journals and articles subjects were read and interpreted in order to generate a clarification of the case under study, such as PubMed, Scielo. The study was carried out considering a search to present the importance on the subject through some studies from 5 years ago.

Results: Articles from journals with the effect of physical exercise in the immunological-co system were analyzed, where it was possible to analyze and observe that the immune system can have a beneficial according to the intensity applied.

Conclusion: It is worth considering in the prescription of the training to calculate and periodize the pre-scribed activity so that we can have a control of the intensity of physical exercise in rela-tion to the immune system. 


\section{(8) \\ INTRODUÇÃO}

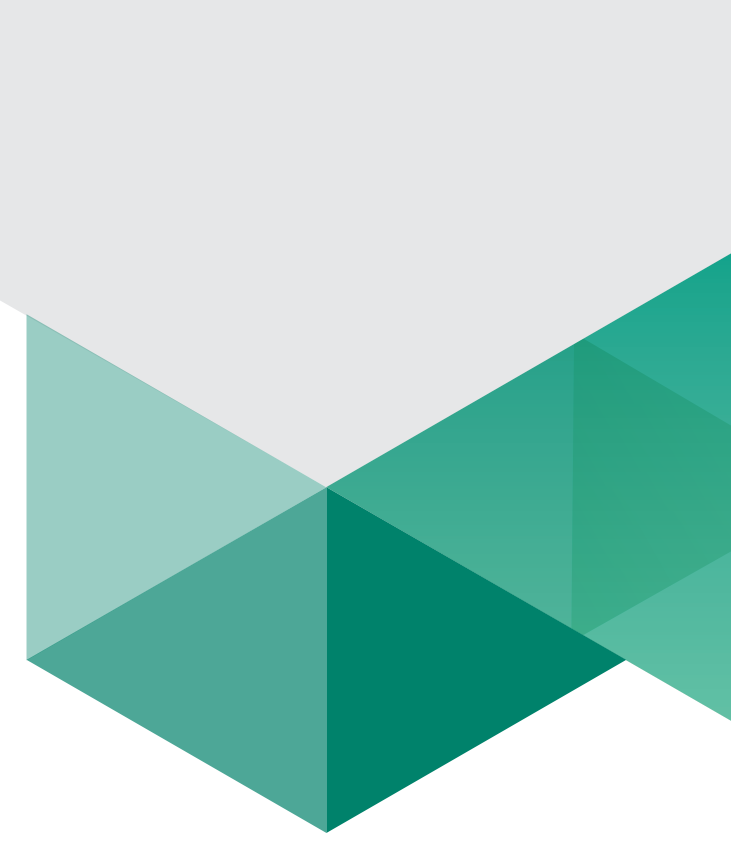

Nos últimos anos a procura por exercício físico vem aumentando constantemente, com uma busca por uma saúde melhor. Vários estudos vêm abordando a correlação da prática do exercício físico a uma melhora do sistema imune. O sistema imunológico é determinante no combate a microrganismos invasores, na remoção de células mortas e detritos celulares e no estabelecimento da memória imunológica (LEANDRO et al., 2002).

Nosso corpo é composto por dois tipos de barreiras que são subdivididas em apta e inapta (adaptativa). A resposta classificada como apta compreende-se como a primeira linha de defesa do nosso organismo representado por barreiras físicas, químicas e biológicas como exemplo pele, cílios, lagrimas, suor, mucos, plaquetas, saliva, suco gástrico podendo ser classificada como leucócitos, neutrófilos e macrófagos. Já a classificada como inapta ou adaptativa é aquela adquirida com o tempo como exemplo anticorpos e vacinas, ela depende de ativação de células especializadas como os linfócitos sendo classificados em B e T (TERRA et al., 2012).

O exercício físico é classificado de acordo com a intensidade, onde podemos elencar dois parâmetros fisiológicos normalmente utilizados em estudos para apontar o mesmo, sendo eles o VO2max e FC. O exercício para ser considerado de leve intensidade é de $20-50 \%$ do vo2max e da FC, moderado 50-70\% do vo 2 max e da FC, intenso a partir de 80\% do vo2max e da FC (LEANDRO et al., 2007).

Quando o indivíduo é submetido a um exercício físico extenuante logo seu sistema imunológico fica mais vulnerável a agentes invasores pois o organismo toca um alarme falso deslocando as células de defesa, e assim leva um tempo para se reorganizar, nesta janela de tempo o corpo fica mais vulnerável. No exercício de alta intensidade há uma baixa na glicemia e da insulina elevando assim os níveis de cortisol no organismo fator esse que contribui na piora do sistema imune deixando assim o corpo mais suscetível a agentes invasores. Para diminuir a ação de alta do cortisol pós exercício, o indivíduo tem como alternativa fazer o uso de uma bebida carboidratada (LEANDRO et al., 2007). 
METODOLOGIA

\section{TIPO DE ESTUDO}

Trata-se de uma revisão bibliográfica com base em artigos e revistas, com o intuito de reunir vários estudos e evidências acerca do efeito do sistema imunológico frente ao exercício físico. Para a realização desse trabalho (revisão) foram realizados estudos com intuito de coletar dados e informações há cerca do tema. Para organização deste objeto de estudo foram lidas, interpretadas revistas adotando-se como técnica norteadora as matérias e assuntos de artigos de forma a criar um conjunto base para esclarecimento do caso em estudo.

\section{CRITÉRIOS DE INCLUSÃO E EXCLUSÃO}

Foram analisadas a resposta do efeito do sistema imune frente ao exercício físico. Para este estudo foram utilizados os bancos de dados do PubMed, SciELO e Epistemoni-kos entre o período de 2002 a 2019. Na pesquisa, foram utilizados os unitermos "Exerci-se; Immune System; Lymphocytes, Neutrophils, Macrophages, Natural Killer Cells".

\section{PROCEDIMENTOS PARA COLETAS DE DADOS}

Para realização desta pesquisa foram elaborados levantamentos em busca de da-dos para estudo, PubMed, SciELO e Bireme.

\section{ANÁLISE DOS DADOS}

Foram analisados dados de revistas cientificas com o objetivo de avaliar o efeito do sistema imunológico em decorrência do exercício físico, onde foi observado através de várias leituras, que é possível ter uma melhora no nosso sistema de defesa contra agentes invasores (IVA's) de acordo com a intensidade aplicada. 


\section{RESULTADOS}

Nessa revisão bibliográfica foram analisados e incluídos 42 artigos na base de da-dos PubMed, SciELO e Bireme, entre o período de 2002 a 2019. Foram utilizados e sele-cionados artigos para filtrar o estudo. Sendo 13 pubMed (3 selecionados), Scielo 23 (4 selecionados), 5 bireme (1 selecionado).

\begin{tabular}{|c|c|c|c|}
\hline $\begin{array}{c}\text { AUTORES/ } \\
\text { ANO }\end{array}$ & $\begin{array}{l}\text { BASE DE } \\
\text { DADOS }\end{array}$ & OBJETIVO DE ESTUDO & RESULTADOS \\
\hline $\begin{array}{l}\text { LEANDRO et } \\
\text { al (2007) }\end{array}$ & Scielo & $\begin{array}{l}\text { abordar alguns aspectos relevantes } \\
\text { da influência do treinamento físico } \\
\text { sobre a função de componentes do } \\
\text { sistema imunológico. }\end{array}$ & $\begin{array}{l}\text { Em muitos tecidos tem-se demonstrado que } \\
\text { a resposta a situações agressivas parece ser } \\
\text { atenuada pelo treinamen-to físico aplicado } \\
\text { previamente, isto é, o treinamento induz } \\
\text { tolerância para situações agressi-vas/estres- } \\
\text { santes. Sugerindo os mecanismos adaptativos } \\
\text { do sistema imunológico em resposta ao trei- } \\
\text { namento físico. }\end{array}$ \\
\hline $\begin{array}{l}\text { KRINSKI et al } \\
\text { (2010) }\end{array}$ & Bireme & $\begin{array}{l}\text { apresentar, através de pesquisa } \\
\text { bibliográfica, os efeitos do exercício } \\
\text { físico nos principais componentes } \\
\text { do sistema imune, bem como sua } \\
\text { ação diante de infecções nas vias } \\
\text { aéreas superiores (IVAS) }\end{array}$ & $\begin{array}{l}\text { A análise da literatura apresentou evi- } \\
\text { dências que o exercício moderado, de } \\
\text { intensidade }<60 \% \text { do Vo2máx com dura- } \\
\text { ção } 60 \text { min, é associado a menores per- } \\
\text { turbações no sistema imune, enquanto } \\
\text { que o exercício vigoroso tem demonstra- } \\
\text { do características opostas, aumentando o } \\
\text { risco de adquirir IVAS. }\end{array}$ \\
\hline $\begin{array}{l}\text { MESQUITA } \\
\text { JUNIOR et al } \\
\text { (2010) }\end{array}$ & Scielo & $\begin{array}{l}\text { resgatar os fundamentos dessa } \\
\text { resposta, que apresenta elevada } \\
\text { complexidade e é constituída por } \\
\text { diversos componentes articulados } \\
\text { que convergem para a elaboração } \\
\text { da resposta imune adaptativa. }\end{array}$ & $\begin{array}{l}\text { As células B e T tem como principais } \\
\text { características atuar e auxiliar o sistema } \\
\text { contra agentes invasores, agindo assim } \\
\text { em outras celular que iram atuar na defe- } \\
\text { sa do organismo. }\end{array}$ \\
\hline $\begin{array}{l}\text { RIGO et al } \\
\text { (2013) }\end{array}$ & pubMed & $\begin{array}{l}\text { Observar-se na literatura que não } \\
\text { há um consenso sobre a influência } \\
\text { do exercício sobre a contageme a } \\
\text { função das células NK. }\end{array}$ & $\begin{array}{l}\text { A intensidade e a duração do exercício } \\
\text { físico, em uma ampla margem, podem } \\
\text { influenciar quantitativa e qualitativamen- } \\
\text { te as células natural killer. Contudo, as } \\
\text { características do estímulo físico ofertado } \\
\text { permeiam as respostas das células natu- } \\
\text { ral killer. }\end{array}$ \\
\hline $\begin{array}{l}\text { Peake et al } \\
\text { (2017) }\end{array}$ & pubMed & $\begin{array}{l}\text { Mostrar que o exercício aumenta a } \\
\text { contagem de células contra invaso- } \\
\text { res, que atual diretamente no siste- } \\
\text { ma imunológico criando barreiras } \\
\text { contra corpos estranhos. }\end{array}$ & $\begin{array}{l}\text { Foram analisandos indivíduos com ate } \\
40 \text { anos, onde foi observado que a con- } \\
\text { tagem de células B e T vem crescendo na } \\
\text { pratica de exercício físico de acordo com } \\
\text { a intensidade e volume aplicada na ses- } \\
\text { são de treino. }\end{array}$ \\
\hline
\end{tabular}




\begin{tabular}{|c|c|c|c|}
\hline $\begin{array}{l}\text { Rosa e Vais- } \\
\text { benberg, } \\
2002\end{array}$ & Scielo & $\begin{array}{l}\text { O artigo mostra a resposta do siste- } \\
\text { ma imune de forma aguda e crôni- } \\
\text { ca, onde ambas têm componentes } \\
\text { semelhantes. }\end{array}$ & $\begin{array}{l}\text { Apesar das incorreções que cometemos } \\
\text { quando das generalizações, podemos } \\
\text { dizer que, de modo geral, o exercício de } \\
\text { intensidade moderada, praticado com } \\
\text { regularidade, melhora a capacidade de } \\
\text { resposta do sistema imune, enquanto o } \\
\text { exercício de alta intensidade praticado } \\
\text { sob condições estressantes provoca um } \\
\text { estado tran-sitório de imunodepressão. }\end{array}$ \\
\hline $\begin{array}{l}\text { TERRA et al., } \\
2012\end{array}$ & Scielo & $\begin{array}{l}\text { Revisar na literatura estudos que } \\
\text { abordem os efeitos promovidos } \\
\text { pelo exercício físico no desenvolvi- } \\
\text { mento da resposta imunológica e } \\
\text { suas possíveis vias de transdução de } \\
\text { sinais. }\end{array}$ & $\begin{array}{l}\text { A literatura disponível mostra que duran- } \\
\text { te a prática de exercício, várias subpo- } \\
\text { pulações de leucócitos são alteradas de } \\
\text { acordo com a intensidade e duração da } \\
\text { atividade desempenhada. Exercícios de } \\
\text { intensidade moderada estimulam uma } \\
\text { resposta pró-inflamatória, enquanto } \\
\text { aqueles de alta intensidade tendem a } \\
\text { promover respostas anti-inflamatórias } \\
\text { visando diminuir os danos na musculatu- } \\
\text { ra esquelética. }\end{array}$ \\
\hline $\begin{array}{l}\text { LEANDRO et } \\
\text { al., } 2002\end{array}$ & pubMed & $\begin{array}{l}\text { O exercício físico induz alterações } \\
\text { transitórias no sistema imunológico, } \\
\text { a intensidade, a duração e o tipo de } \\
\text { exercício determinam as alterações } \\
\text { ocorridas durante e após esforço. }\end{array}$ & $\begin{array}{l}\text { Neste artigo, são relatados estudos evi- } \\
\text { denciando a influência dos diferentes } \\
\text { tipos de exercício físico sobre a concen- } \\
\text { tração e a função de componentes do sis- } \\
\text { tema imunológico. Serão ainda discutidos } \\
\text { pontos relevantes da integração entre o } \\
\text { sistema nervoso, o sistema endócrino e } \\
\text { em particular o sistema imunológico du- } \\
\text { rante o exercício físico. }\end{array}$ \\
\hline
\end{tabular}

\section{DISCUSSÃO}

Imunoglobina: As imunoglobinas também conhecidas como anticorpos que podem ser subdivididos em 5 tipos: IgA, IgD, IgE, IgG, IgM. Ela pode ser considerada como primeira barreira contra microrganismos, se o indivíduo faz exercício físico intenso pode ocorrer uma grande queda na produção de IgA assim facilitando a invasões no sistema imune. No entanto exercício moderado a produção de IgA permanecem estáveis ou até mesmo se tem uma melhora na função contra invasores (KRINSKI et al., 2010).

Leucócitos: São células sanguínea, também conhecidas como glóbulos brancos que atuam na defesa do nosso organismo, podendo ser classificados em dois tipos: granulócitos e agranulocitos. Os agranulócitos são subclassificados em linfócitos e monócitos, e os granulócitos e subdividem em eosinofilos, basófilos e neutrófilos. Peake (2017) cita que uma única sessão de exercícios causa mudanças profundas no número e na composição dos leucócitos sanguíneos que podem persistir por muito tempo na recuperação do exercício. O número de neutrófilos (e, consequentemente, a contagem total de leucócitos) muitas vezes continua a aumentar durante o período de recuperação (até 6 horas após a interrupção do exercício), principalmente se a sessão de exercício for pro-longada.

Com a pratica de exercício físico de alta intensidade (acima de 60\% do VO2max) há uma "lifope- 
nia" em apenas 30 minutos de exercício extenuante, podendo chegar até $50 \%$ do nível pré exercício, a mesma é restaurada ao nível basal após 4 > 6 de recuperação. (ROSA E VAISBERG, 2002).

Citosinas: Sempre que o indivíduo tem uma infecção ou ferimento ocorre a ativação na produção de moléculas proteicas que também podem ser conhecidas como citosinas. Sendo ativadas no local do ferimento. Citosinas são moléculas que são lançadas no local da inflamação como agentes facilitando a ação dos linfócitos neutrófilos, monócitos participando na restauração dos tecidos lesados. O exercício tem uma influência direta nas citosinas, durante a contração muscular ocorre micro lesões e logo em seguida se tem uma resposta inflamatória aguda, tem como participação direta necrose e outras citosinas que durão por vários dias com o intuito de restaurar o tecido lesado esse processo vai depender da intensidade e duração do exercício (KRINSKI et al., 2010).

Linfócitos: Para a origem dos linfócitos T e B são geradas na medula óssea, células progenitoras mieloides e linfoides. Os linfócitos T deixam a medula óssea e posteriormente entram em seleção e maturação no timo, apenas os (LT) maduros caem na corrente sanguínea. Diferentemente dos linfócitos T, o B perdura na medula óssea onde iriar ocorrer sua maturação, migrando para a circulação (MESQUITA JUNIOR et al., 2010).

Natural killer (NK): Entre os linfócitos, as NK são compostas por 10\% do número total de células, desempenham duas funções muito importante em nosso organismo, como característica destruir células infectadas, e ativar macrófagos. Com o exercício físico pode haver um alteração na contagem e nas funções das células NK, isso depende do tipo de exercício, duração, intensidade, e treinabilidade de cada indivíduo, tal fator se deve ao estresse promovido pelo esforço, por tanto, durante exercício extenuante a concentração da NK pode ficar abaixo do seu valor basal, havendo uma queda de $40 \%$ que podem levar até 7 dias para se recuperar (RIGO et al., 2013).

Com o estimulo agudo a contagem de NK pode aumentar em até 5 vezes sua contagem em relação aos níveis basais, sabe-se que o exercício físico auxilia no recrutamen-to de células NK (RIGO et al., 2013). 


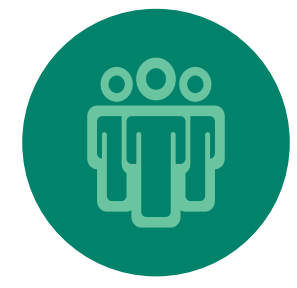

\section{CONCLUSÃO}

A prática regular de exercício físico pode ser benéfica para a saúde, porém, parâmetros como volume e intensidade devem ser observados em sua prescrição para que dele se obtenha melhores resultados. Vistos nos achados em artigos e revistas, mostram que o exercício físico age de forma a colaborar no sistema imune de acordo com a inten-sidade aplicada em cada sessão. O sistema imune irar responder através da carga impos-ta no treino, onde o papel do educador físico é de crucial importância para a prescrição de treinos, ele irar controlar, manipular e observar o resultado. 


\section{REFERÊNCIAS}

Kleverton Krinski, Hassan Mohamed Elsangedy, Heriberto Colombo, Cosme Franklim Buzzacher Physical exercise effects in the immunological system RBM rev. bras. med ; 67(7)jul. 2010.

Rodrigo Terra, Ś́lvia Amaral Gon.alves da Silva,Veronica Salerno Pinto, Patrícia Maria Lourenço Dutra. Efeito do exercício no sistema imune: resposta, adaptação e sinalização celular. Rev Bras Med Esporte - Vol. 18, No 3 - Mai/Jun, 2012

Carol Leandro, Elizabeth do Nascimento, Raul Manhães-de-Castro, José Alberto Duarte, Célia M.M.B. de-Castro. Exercício físico e sistema imunológico: mecanismos e integra-ções. Revista Portuguesa de Ciências do Desporto, 2002, vol. 2, no 5 [80-90]

Carol Góis Leandro, Raul Manhães de Castro, Elizabeth Nascimento, Tânia Cristina Pithon-Curi; Rui Curi. Mecanismos adaptativos do sistema imunológico em resposta ao treinamento físico. Rev Bras Med Esporte vol.13 no.5 Niterói Sept./Oct. 2007

Jonathan M. Peake, X Oliver Neubauer, Neil P. Walsh, and Richard J. Simpson Recovery of the immune system after exercise. J Appl Physiol 122: 1077-1087, 2017. First publis-hed December 1, 2016; doi:10.1152/japplphysiol.00622.2016.

Luiz Fernando Pereira Bicudo Costa Rosa; Mauro W. Vaisberg Influências do exercício na resposta imune Exercise influence on immune response. Rev Bras Med Esporte vol.8 no.4 Niterói July/Aug. 2002

Fabiano Dall'Asta Rigo, Moacir Pereira Junior, Daiane da Rosa, Francisco Navarro, Fabio Henrique Ornellas. O exercício físico e as células natural killer: uma revisão sistemática da literatura. FEMINA I Maio/Junho 2013 | vol 41 | no 3

Danilo Mesquita Júnior, Júlio Antônio Pereira Araújo, Tânia Tieko Takao Catelan, Alexandre Wagner Silva de Souza, Wilson de Melo Cruvinel1, Luís Eduardo Coelho Andrade, Neusa Pereira da Silva. Sistema Imunitário - Parte II Fundamentos da resposta imunológica mediada por linfócitos T e B. Rev Bras Reumatol 2010;50(5):552-80 